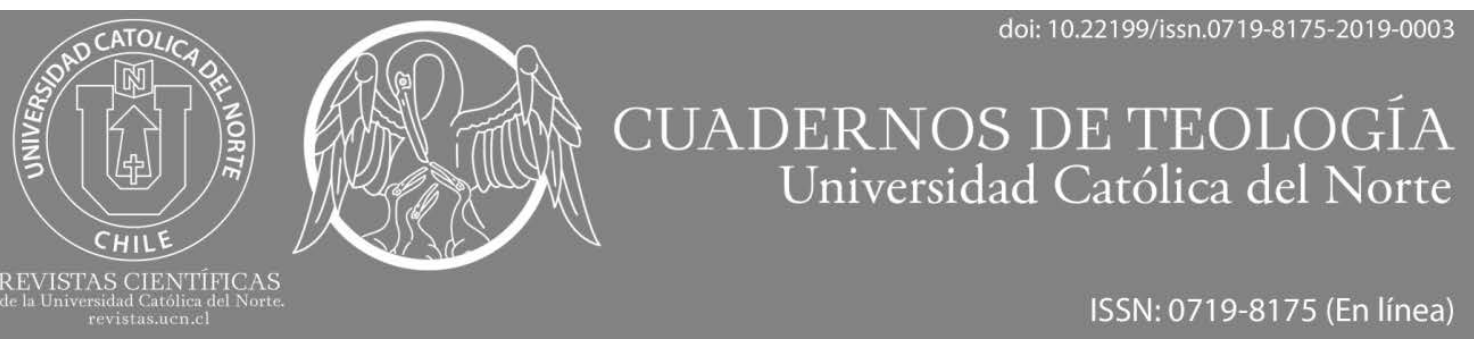

\title{
Religación y Gracia en el pensamiento de Xavier Zubiri
}

\section{Religation and Grace in Xavier Zubiri's thought}

\section{Ignacio Sepúlveda del Río* (D) https://orcid.org/0000-0001-7919-1011}

*Universidad Loyola Andalucía. Profesor. Departamento de Humanidades y Filosofía, Sevilla, España. Ph. D. en Filosofía Moral y Política, U. de Valencia

๑ isepulveda@uloyola.es

(cc) BY

\section{Resumen:}

En la obra de Zubiri nos encontramos con una extensa reflexión en torno al problema de Dios y su relación con el ser humano. En el presente artículo se busca presentar cuáles son las ideas claves de este pensamiento desde la filosofía zubiriana, y cuál sería su traducción a una teología que ponga en relación al Creador con la creatura desde una donación del Primero y una transformación de la segunda.

Palabras Clave: Existencia humana; Deificación; Realidad; Existencia de Dios; Trinidad; Gracia (teología).

\section{Abstract:}

We can find in Xavier Zubiri's work a large reflection on the problem of God and His relationship with the human being. On this article we are looking to show what are the key ideas of this thinking from a zubirian philosophical perspective. We will also try to show how this philosophical thinking can be translated into a theology, which is able to put in relation the Creator with the creature from a dual perspective: the donation of the First and the transformation of the second.

Keywords: Human existence; Deification; Reality; Good-proof; Trinity; Grace (theology). 


\section{Introducción}

A lo largo de su vida Xavier Zubiri tuvo una preocupación constante, tanto filosófica como teológica, sobre el tema de la religión y de Dios. Esta preocupación se puede reconocer en sus obras (algunas publicadas en vida y otras póstumamente) y también en los numerosos cursos que dedicó al respecto. Es muy sugerente constatar que, para el filósofo vasco, la religión y la relación con Dios parten desde el hecho de la realidad y de la ligazón (religación) del humano con ella. Desde la realidad y el poder que ella ejerce se puede entender la experiencia de Dios. De esta manera, el encuentro con Dios se daría en una trascendencia inmanente.

En este artículo nos planteamos como preguntas fundamentales, a partir del pensamiento de Zubiri, dónde y cómo se encuentra el hombre con Dios. Para responder a estas preguntas debemos inquirir, en primer lugar, sobre la naturaleza del hombre: ¿qué es?, ¿desde dónde se fundamenta?, ¿cuál es su estructura fundamental? Desde la respuesta a esta pregunta, podemos preguntarnos por el hombre con relación a Dios. ¿Hay alguna relación? ¿Existe cercanía entre el Creador y la creatura o sólo un abismo ontológico insalvable? Para respondernos a estas preguntas indagaremos, especialmente, en el pensamiento que Xavier Zubiri (1998) desarrolla en su obra El Hombre y Dios.

Habiendo respondido filosóficamente a la pregunta sobre la naturaleza del hombre y su relación con el Creador, vamos a ver cómo este pensamiento puede "decirse" de manera teológica. Para este fin utilizaremos El Problema Teologal del Hombre: Cristianismo. En esta obra nos centraremos especialmente en el problema de la deificación, que es un concepto central en el pensamiento teológico zubiriano.

\section{La realidad como fundamenta- lidad}

\subsection{La realidad como problema}

Cuando Zubiri se pregunta por el hombre lo primero que destaca es que el ser humano es, ante todo, una realidad, la realidad humana. Esta pregunta envuelve en sí dos términos: realidad y humanidad. Para comprender a cabalidad lo que el autor quiere exponer, es necesario que nos detengamos un momento para aclarar, brevemente, qué entiende por "realidad". Ignacio Ellacuría, al reflexionar sobre el problema de la realidad en Zubiri, afirma que "Zubiri prefiere la línea del enfrentamiento inmediato con las cosas, fiel a su idea de la inteligencia de la reactualización de lo real, en tanto que real" (Ellacuria, 1999, p. 403). De esta manera, el carácter de realidad se manifiesta no solo como mera formalidad, sino como el carácter último por el que la metafísica indaga.

Todo lo real está constituido por ciertas notas. Zubiri usa la palabra nota, y no "propiedades", por dos razones: la nota pertenece a la cosa y, por otro lado, nos notifica lo que la cosa es según esta nota. De esta manera el calor es una nota de la cosa $y$, al mismo tiempo, nos notifica lo que es la cosa. Ahora bien, ¿qué entiende Zubiri por realidad? La realidad es que las notas de algo pertenecen a la cosa "de suyo":

"Entiendo por realidad de algo el que estas notas pertenezcan a la cosa "de 
suyo", es decir, que no sean tan sólo signos de respuesta. Así, para el perro, el calor "calienta", es decir le impone un modo de conducta: acercase, huir, etc. Pero para nosotros, hombres, ante todo el calor "es caliente". Sus caracteres le pertenecen "de suyo". Y por esto al estar así aprehendido "de suyo" el calor tiene lo que llamaré formalidad de lo real. No es meramente estimulante. Realidad no significa aquí existencia, y mucho menos algo allende mi aprehensión, sino que es la formalidad según la cual eso que llamamos calor está aprehendido como algo "de suyo", es decir, según la formalidad de realidad. La existencia misma pertenece al contenido de lo real y no a la formalidad de realidad. Todas las notas, además de un contenido propio y de su propia existencia, tienen una formalidad de alteridad distinta según sea el aprehensor. Para el animal la formalidad de lo aprehendido es mera estimulidad; para el hombre lo aprehendido es "de suyo", es realidad". (Zubiri, 1998, p. 19)

Este aprehender "de suyo" no significa que aprehendamos mesas, sillas, paredes, etc. Lo que se aprehende es una cosa, una constelación de notas. Jamás aprehendemos algo así como una mesa. El sentido de las cosas, la "cosa-sentido", es distinto a la "cosa-realidad"1, la cual sería un momento posterior. La "cosasentido" sería el planteamiento de Heidegger. Zubiri, en cambio, estaría ubicado en un nivel más primario o radical que es

${ }^{1}$ Con respecto a la relación entre realidad y sentido, se puede consultar la obra de Pintor Ramos (1993). anterior al sentido ${ }^{2}$. Sobre la realidad entendida como "de suyo", Rivera (2001) señala:

"«De suyo» es el modo como se manifiesta la realidad a la inteligencia sentiente. No es el 'de suyo' un carácter que surja por la intelección, sino al revés, es ésta la que en su estructura formal propia remite, según Zubiri, a lo que la realidad misma es como realidad: algo que ya es anteriormente a la intelección. La intelección envuelve en sí misma como momento constitutivo suyo este ya, este prius de la realidad. De la manera que la intelección viene a ser la actualización en la inteligencia de la realidad como algo que ya es antes de su intelección. Este prius de la realidad es precisamente el carácter de «de suyo»". (pp. 151-152)

La intelección sentiente, por lo tanto, es anterior a toda conceptualización, pues entra de manera inmediata en contacto intelectivo con las cosas. Aquí se establece una diferencia con la Escolástica:

"Pues bien, para la Escolástica, este enfrentamiento, es decir, el acto propio y formal de la inteligencia es "concebir»; basta recordar, en efecto, que se comienza por decir que lo primero que "concibe» la inteligencia y aquello en que todos sus "conceptos» se resuelven es el ente. Fijado así, según la Escolástica, la manera primaria de aprehender intelectivamente las cosas, de ella es de la que arranca su idea de realidad." (Zubiri, 1985, p. 389)

\footnotetext{
2 Sobre las diferencias de la filosofía de Zubiri con respecto a la fenomenología, se puede consultar la obra de Pintor Ramo (1996).
} 
Rivera entiende que el concepto zubiriano de realidad como "de suyo" es anterior a la existencia y a la esencia clásicas, además de ser algo distinto de la objetualidad y anterior al ser. Zubiri (1995) afirma al respecto:

"La realidad no es un modo de ser. La realidad es justamente algo previo al ser. $Y$ el ser es algo que está fundado en la realidad como un de suyo. De ahí que él problema del devenir afecta primaria y radicalmente a la realidad. No afecta al ser. Afecta al ser derivativamente, en la medida en que el ser es la segunda actualidad, la reactualización de una realidad en su respectividad. Pero el devenir es anterior justamente a toda articulación de ser $y$ de no-ser, porque es algo que incide sobre la realidad en tanto que realidad, y en tanto que ésta, reduplicativamente, es anterior al ser" (p. 30).

\subsection{La realidad humana}

Habiendo aclarado la pregunta por la realidad, podemos entrar a investigar la pregunta por la realidad del ser humano.

Cada hombre es una persona codeterminada frente a la realidad. Está codeterminada individual, social e históricamente. En esta realidad el hombre está llamado a ejecutar sus acciones, de manera que puede ser agente de ellas. Al ser agente de sus acciones es agente de su vida, se posee a sí mismo. Ahora bien, la vida de cada persona no comienza desde la nada, en el vacío, sino que un contexto vital determinado: época, sociedad, la propia individualidad, lenguaje, etc. Cada hombre es agente de su propia existencia en un contexto vital determinado que lo enmarca:
"La vida del hombre no es solamente la vida que él ejecuta sino que es a la vez, y intrínsecamente, en algún aspecto, la vida que le ha caído en suerte, por así decirlo. Según la zona temporal, según el marco social, según el modo peculiar de la individualidad que le ha sido dada, el hombre vive en el perfil de un contexto ya parcialmente trazado"(Zubiri, 1998, p. 77).

Hemos dicho que cada persona es agente de su propia vida, que se autoposee. Este ser agente trae aparejado el optar; esto es adoptar en cada acción suya por una forma determinada de realidad entre varias posibles ${ }^{3}$. En este aspecto el hombre es autor de su vida. Al optar y ejecutar las acciones, el hombre realiza su vida personal, se realiza como persona y va cobrando realidad como relativamente absoluto.

¿Qué es esto de "relativamente absoluto"? El hombre es una realidad relativamente absoluta. Esto significa que el hombre está "enfrentado" a todo lo demás. Por su propia realidad el hombre está forzosamente "frente-a" todo lo demás. Sin estar "frente-a" no se puede ser persona humana. Por su propia realidad al hombre le está impuesta esta necesidad de estar "frente-a". Esto es un absoluto, pero un absoluto relativo. La persona va haciendo su realidad relativamente absoluta frente a todas las cosas cuando realiza acciones "con" las cosas. Para el hombre, vivir es poseerse realmente estando "con" las cosas "en" la realidad: "En definitiva,

\footnotetext{
${ }^{3}$ Cfr. López Aranguren (1981, p. 47), el análisis que hace a este respecto es muy clarificador: lo humano y lo moral es poder elegir. Por eso el ser humano es un ser, esencialmente moral.
} 
vivir $^{4}$ es poseerse a sí mismo como realidad estando con las cosas en la realidad" (Zubiri, 1998, p. 81).

\section{La religación ${ }^{5}$ como funda-} mento

La realidad, tal como hemos afirmado más arriba, es el fundamento del ser humano. Esta es la razón por la cual el hombre está fundado en la realidad como tal. De esta manera, la realidad adquiere fundamentalidad. La realidad es fundamento en un triple sentido. Ella es algo último en las acciones humanas, así es fundamento como ultimidad. Segundo, el hombre como agente de sus actos opta en cada acción por una forma determinada de realidad que se le da como posibilidad entre otras. Así, la realidad es la posibilidad de todas las posibilidades, pues ella posibilita que la realidad del hombre sea humana. Por último, la realidad también es impelente. El hombre tiene que ejercer una acción (aún si no lo hace lo está haciendo). La realidad impone al hombre su realización como persona relativamente absoluta. Este carácter de la realidad como fundamento -la fundamentalidad de la realidad- es lo que Zubiri llama el "poder de lo real".

Teniendo en cuenta este triple sentido de la realidad como fundamento, se puede decir que el hombre vive "en" la realidad, "desde" la realidad y "por" la

\footnotetext{
${ }^{4}$ Este vivir, obviamente, se refiere al vivir humano.

${ }^{5}$ El concepto religación fue introducido en 1935 por Xavier Zubiri. El problema de tan novedoso concepto es que pocas veces se comprendía su significado a cabalidad. Diego Gracia, al comentar el origen de este concepto, señala que surge del diálogo con Heidegger. Para Zubiri, a diferencia de Heidegger, el ser humano más que estar lanzado, geworfen, está reatado a la realidad; es decir, está religado. Cfr. Gracia (2013, p. 186).
}

realidad. De esta manera ella es fundamento posibilitante e impelente.

"La realidad funda mi ser personal
según estos tres caracteres que posee
como ultimidad, como posibilitación
y como impelencia. Estos caracteres
constituyen la fundamentalidad de lo
real." (Zubiri, 1998, p. 84)

El poder de lo real que es, tal como hemos señalado, ultimidad, posibilidad e impelencia es lo que Zubiri llamará "deidad". Este concepto no debe llevar a confusión: la deidad no es Dios, sino la propia realidad intramundana como poderosa y religante. Zubiri entiende que toda cultura ha tenido esta experiencia de la fuerza y el poder de la realidad: en las culturas más primitivas este poder se ha manifestado como el animismo o la magia. En otras culturas antiguas este poder se ha entendido como los dioses.

"Deidad no es, pues, un vaporoso carácter pseudo-divino sino que es la realidad misma de las cosas en cuento como poder manifiesta su formal constitución en Dios. Los griegos decían que la Naturaleza, la Physis, es divina, es theíon, porque según ellos es inmortal e inagotable, es decir, siempre joven. Esto no es hoy admisible desde ningún punto de vista. Pero sin embargo, los griegos rozaron con ello algo esencial que ha ocupado ningún lugar propio en la filosofía: el carácter de las cosas que ni son dioses ni son divinas, pero que sin embargo tienen algo de este carácter: son formalmente deidad. Las cosas reales en cuanto reales son la deidad que manifiesta a Dios, que está en ellas formalmente constituyéndolas. $Y$ por este carácter de deidad es por lo 
que son manifestación, vehículo de Dios" (Zubiri, 1998, p. 156).

La realidad determina físicamente al hombre como absoluto relativo: lo domina. Dominar no es causar ni tener más importancia. Dominar es ser más, es tener poder. Es ser más en el sentido de no estar "constreñido-por". Esto significa que la realidad no está constreñida por la talidad $^{6}$; la realidad domina la talidad porque la primera es más que la segunda. Esto no significa que la realidad está fuera de las talidades, pues no hay una realidad al margen de las cosas reales, sino que la realidad es más que la mera talidad.

Hay una constitutiva respectividad del hombre al poder de lo real. Gracias a ella el hombre es persona. Esto significa que el hombre es persona porque la realidad se apodera de él y lo hace hacerse a sí mismo. La realidad le permite al hombre ser real: "La realidad es fundante de una realidad personal por el apoderamiento según el poder de lo real" (Zubiri, 1998, p. 88). El hombre viene de la realidad y apoderado por ella está implantado en ella. Este apoderamiento de la realidad sobre la persona liga al hombre al poder de lo real. Estamos religados no a los entes, sino que al fundamento de todos los entes. En este sentido se puede entender la religación como trascendente, pero en la inmanencia.

El apoderamiento es un momento constitutivo de la realidad personal. Pero este apoderamiento es paradójico pues, al apoderarse de nosotros, nos hace estar constitutivamente sueltos "frente-a" aquello que se ha apoderado de nosotros.

\footnotetext{
${ }^{6}$ El concepto "talidad" en Zubiri significa "tal" cosa o "tal" otra. Así se da la "talidad".
}

El apoderamiento acontece ligándonos al poder de lo real. Esta ligadura será llamada por Zubiri religación. Para nuestro autor este es un hecho constatable y no una mera teoría 7 . El hombre está religado al poder que lo hace ser real. Ante esta religación no cabe más que doblegarse y reconocer que existe:

"Me encuentro pues religado a la realidad en su poder. La religación es religación al poder de lo real. El hombre es relativamente absoluto precisa y formalmente porque está religado a la realidad como poder. La fundamentalidad acontece en la religación al poder de lo real" (Zubiri, 1998, p. 94).

La religación implica que el hombre hace una experiencia ${ }^{8}$ del poder de lo real. El hombre la experimenta en su propia persona cuando hace la probación física de la realidad como poder que sigue rutas individuales, sociales e históricas. Por otro lado, la religación, como una de sus notas características, manifiesta el poder de lo real.

\footnotetext{
${ }^{7}$ Al respecto, Gracia (2010) señala que la religación "es un dato primario, surgido de la mera descripción de lo dado en impresión de realidad, en tanto que dado en ella" (p. 494).

${ }^{8}$ Conviene recordar que Zubiri no entiende "experiencia" como un dato sentible (aísthesis) ni tampoco con la empeiría de Aristóteles; es decir, experiencia no es el dato empírico. Zubiri (1998) entiende que la experiencia es "el ejercicio mismo operativo del acto de probar: es probación física" ( $\mathrm{p}$. $95)$. De esta manera, la experiencia es probación física de la realidad. El ser humano se dirige a la realidad para buscar un apoyo en ella. La realidad, con su riqueza y diversidad de notas, abre posibilidades de realización. Por eso Zubiri (1998) entiende que "la inserción de estas posibilidades en la realización de mi persona es la probación física de realidad. El hombre, haciendo religadamente su persona, está haciendo la probación física de lo que es el poder de lo real. Es la probación de la inserción de la ultimidad, de la posibilitación y de la impelencia en mi propia realidad" (p. 95).
} 
La religación al poder de lo real manifiesta el carácter enigmático de este poder, según Zubiri (1998), pues las cosas exigen al hombre estar en la realidad, pero ninguna de ellas es "la" realidad en la que exigen estar. La realidad se presenta como un "más":

"Toda cosa humanamente aprehendida es real, pero ninguna es "la" realidad. Es lo que expresábamos diciendo que las cosas reales vehiculan el poder de lo real, son sus vectores. No son dos realidades, sino una sola, una unidad enigmáticamente manifiesta en nuestra religación experiencial. Tenemos que estar en la realidad, nos lo exigen las cosas reales en su realidad, pero ninguna es aquello en que se nos hace estar. Es el poder de lo real como enigma: estar en "la" realidad con las cosas reales" (p. 97).

En base a lo anterior, Zubiri (1998) concluye que la fundamentalidad de la realidad es problemática. Esta problematicidad se expresa de varios modos. El primero de ellos sería la inquietud: el enigma de estar religado inquieta al hombre: "La realidad humana tiene una vida, y esta vida es constitutivamente inquieta porque la realidad en que se vive es enigmática" (p. 100). Esta inquietud se puede expresar en dos preguntas: ¿Qué va a ser de mí? Como esta realidad que soy yo no está dada, sino que la tengo que hacer, esta pregunta deriva en otra mucho más apremiante: ¿qué voy a hacer de mí?

Esta inquietud que emerge de la vida del hombre tiene su contrapartida en lo que el filósofo vasco denomina la voz de la conciencia ${ }^{9}$. Se suele hablar de la voz de la conciencia cuando se habla de deberes, especialmente los deberes morales. Pero esta voz es más que eso ${ }^{10}$. Desde lo más profundo del ser humano surge una voz ${ }^{11}$ que, de alguna manera, le dicta lo que debe hacer o no hacer, pero, sobre todo, le dice lo que ha de ser:

"La voz de la conciencia puede ser clara, oscura, incluso variable, porque esta voz dirá probablemente a un europeo cosas muy distintas de las que tal vez puede decir a un chino o a un japonés (no lo sé). Y en todos estos casos dictados lo que la voz de la conciencia dicta como algo que emerge del fondo de mi propia realidad, es justamente una forma de realidad que he de adoptar. En esto consiste formalmente el dictado de la voz de la conciencia" (Zubiri, 1998, p. 102).

La voz de la conciencia es la voz de la realidad camino de lo absoluto, en el sentido de que lanza al ser humano hacia el poder de lo real como enigma. Al respecto Zubiri (2017) señala que la voz de la conciencia "es el atenimiento de la reali-

\footnotetext{
${ }^{9} \mathrm{Al}$ respecto conviene ver el trabajo del profesor Conill (2009) sobre el tema. En esta investigación Conill cita a Diego Gracia, quien afirma que el término procede de Heidegger.

10 Sobre la voz de la conciencia, Zubiri (2017) afirma: "Perdón por la palabra "conciencia". Aquí la palabra "conciencia" no está tomada en el sentido filosófico de "darme cuenta de-". Tampoco en el sentido moral, bien entendido, sino en el sentido, en fin, más o menos corriente, que todos lo comprendemos, para no entrar en largas disquisiciones sobre lo que es la conciencia, cuando digo que tenemos la voz de la conciencia" (p. 427).

${ }^{11}$ Zubiri no se refiere al "fondo" de manera psicológica. Si fuera fondo psicológico, no podría constituir la voz de la conciencia si no saliera de un fondo más radical. Sobre la crítica zubiriana a la voz de la conciencia como fondo psicológico se puede consultar Zubiri (2017, pp. 430-432).
} 
dad, que precisamente tiene un carácter absoluto, porque no es otra cosa sino la resonancia de la realidad en mí" (p. 434).

Por último, esta problemática se expresa en la volición. El hombre está "frente-a" las posibilidades. Debe tomar alguna y hacerla su forma de realidad. Aun cuando no quiera elegir, como se ha dicho antes, ya está eligiendo, optando por algo (en este caso el no elegir, no es sino un elegir que constituye un tipo de realidad).

La volición es voluntad de realidad, pues la apropiación de posibilidades se da en orden a una forma de realidad. Ya que la realidad actualizada en la intelección es la verdad, la voluntad de realidad debe ser voluntad de verdad. Atendiendo a esto podemos decir que la realidad-fundamento es verdad real.

La voluntad de verdad real se plasma en una búsqueda. Es la búsqueda de la manera como las cosas reales se articulan en la realidad para poder adoptar una forma de realidad.

\section{El Hombre como experiencia de Dios}

Según Zubiri, Dios está presente fundantemente en el fondo de las cosas $y$, de modo especial, en el fondo de las personas. Varios años antes de escribir EI Hombre y Dios, Zubiri afirmaba que el hombre no necesita llegar a Dios, sino que está viniendo desde Dios. Por esta razón, la religación con Dios sería anterior al sentimiento ${ }^{12}$ de necesidad religiosa:

\footnotetext{
${ }^{12}$ Con respecto a la emoción religiosa y a la influencia del vitalismo orteguiano en el joven Zubiri, se puede consultar el trabajo de Conill (2006).
}

"Como Dios es algo que afecta al ser mismo del hombre, resulta caduca toda discusión acerca de las "facultades" que primariamente nos llevan a Él. Dios está patente en el ser mismo del hombre. El hombre no necesita llegar a Dios. El hombre consiste en estar viniendo de Dios, y, por tanto, siendo en El. Las aspiraciones del corazón son de suyo una vaguedad romántica que de nada nos serviría. Esos arrebatos o arrobos hacia el infinito, esa sentimentalidad religiosoide, es, a lo sumo, indicio y efecto de algo más hondo: del ser del hombre en Dios" (Zubiri, 1971, p. 377).

Diego Gracia entiende que el planteamiento de Zubiri para acercarse a Dios parte desde un planteamiento experiencial que es más básico que la racionalidad:

"Hay que ir a dimensiones más bási-
cas, claramente prerracionales. No
vale utilizar el principio lógico de ra-
zón suficiente, al modo como hacía,
por ejemplo, Leibniz. Es un principio
claramente proposicional y predicati-
vo. La verdad no puede cimentarse
ahí. Ha de haber una dimensión pre-
via, antejudicativa y antepredicativa.
El ente no sólo se juzga, también, y
previamente, se muestra, se revela, es
patente" (Gracia, 2006).

Zubiri entiende que hay una unidad peculiar entre Dios y el hombre. Por razón de Dios, Dios es experiencia del hombre y, por razón del hombre, el hombre es experiencia de Dios. ¿Qué significa esto? Esta experiencia tiene dos lados: por parte de Dios, Dios es una realidad que de algún modo se da en la experiencia. Por 
parte del hombre, éste está experienciando la realidad de Dios.

¿Por qué Dios es experiencia del hombre? Dios da-de-sí la realidad y no puede no dar: tal es su realidad y por esto es fundante de toda realidad. Dios está trascendentemente presente en todas las cosas de manera continua, constante y constitutiva. Es realidad fontanal:

"Como ya hemos dicho anteriormente, Dios es quoad nos et quoad omnes res una realitas fundamentalis. No es un ente supremo sino una realidad fundamental, absolutamente absoluta (...) Es fundamento en la medida en que es transcendente a las cosas, pero en las cosas. $Y$ es transcendente en las cosas, y las está fundamentando, en la medida en que es realidad absolutamente absoluta. No es que Dios fundamente las cosas formalmente en tanto que inteligencia volente. Dios es realidad absolutamente absoluta, y en tanto que absolutamente absoluta es como está fundamentando las cosas, aunque en esta fundamentación no entren formalmente el carácter de inteligencia y el carácter de voluntad. Dios es realidad absolutamente absoluta que es trascendente a lo real" (Zubiri, 1998, p. 311).

Toda la creación es la vida de Dios ad extra. Esta vida ad extra es forma finita. Zubiri dice que hay dos modos fundamentales de creación, dos tipos diferentes de realidad: por un lado, están las esencias cerradas, de las cuales Dios es la fuente de lo que son "de suyo". Por otra parte, están las esencias abiertas, respecto de las cuales Dios se da en donación personal de su propia verdad real con todas sus dimen- siones. De esta manera es que Dios es la experiencia del hombre; experiencia a través de la cual el hombre se constituye como tal.

La experiencia de Dios no es la experiencia de un objeto llamado Dios. Ni es un estado en que el hombre está. La experiencia de Dios por parte del hombre consiste en la experiencia de ser fundamentado en última instancia en la realidad de Dios: "En la experiencia de Dios lo que hay es la experiencia de la realidad fontanal y fundamentante de Dios en la religación como ultimidad, como posibilidad última, y como impelencia suprema" (Zubiri, 1998, p. 326).

La experiencia de hacernos personas es la experiencia de lo absoluto. Dios es aquello que está fundando y haciendo posible lo absoluto de nuestro ser: " $L a$ experiencia de Dios no es otra cosa sino la experiencia de lo absoluto cobrado en la constitución de mi ser, la experiencia de estar fundado en una realidad fundante" (Zubiri, 1998, p. 328).

Así, Dios se da como absoluto en la experiencia: sea en la experiencia de todos los hombres, sea en la experiencia de la gracia, sea en la experiencia de la encarnación del Verbo, de Jesucristo, experiencia que se dimensiona individual, social e históricamente.

Ya hemos dicho que Dios es experiencia del hombre, pero hay que dar un paso más y decir que el hombre es experiencia de Dios. Ser hombre consiste en la experiencia de estar fundado en la realidad fundamental de Dios. El hombre, según Zubiri (1998), es Dios de manera finita: 
"En efecto, el hombre es una manera finita, entre otras muchas posibles, de ser Dios real y efectivamente. Y lo que Ilamamos naturaleza humana es no otra cosa sino ese momento de finitud, que puede ser múltiple y vario, pero que en el caso del hombre es una estructura determinada. El animal de realidades ${ }^{13}$ es el momento de finitud, con el cual el hombre es Dios. El hombre es una manera finita de ser Dios" (p. 327).

Dios no es objeto ni es estado del hombre. Es lo absoluto de su ser. La experiencia de Dios se da en la totalidad de la persona como voluntad de verdad, pero no sólo así. También se da, como hemos dicho anteriormente, como gracia y, sobre todo, se da en la vida humana de Cristo. Esta es una experiencia individual, social e histórica.

\section{Naturaleza y Gracia}

Anteriormente hemos visto, desde el punto de vista filosófico, qué es el hombre y su naturaleza para Zubiri. El ser humano es un ser que se autoposee. Vivir no es sino poseerse a uno mismo como estando en la realidad. De esta manera, el hombre es un Absoluto relativo (dejando el Absoluto-Absoluto para Dios). Es absoluto, por estar "frente-a" las cosas, pero también relativo, pues realiza sus acciones "con" las cosas. Está, por decir de alguna manera, "impelido" a la acción por la realidad.

Junto con lo anterior, hemos dicho que el hombre está religado a la realidad. Esto no es una teoría para nuestro autor,

\footnotetext{
${ }^{13}$ El ser humano.
}

sino una realidad. Estamos "ligados" al poder de lo real. Esta religación, en último término, es una religación a Dios. Todo ser humano está religado a Dios.

Zubiri también distingue entre esencias cerradas y esencias abiertas. Las primeras serían las "cosas" respecto de las cuales, como dijimos anteriormente, Dios es la fuente de lo que son "de suyo". Las esencias abiertas, el hombre, tienen como característica que Dios se da en donación personal a ellas. De esta manera Dios es la experiencia del hombre en la que éste se constituye como tal.

Todo esto lo hemos ya señalado en el curso de nuestra investigación. La pregunta que debemos enfrentar ahora es cómo Zubiri piensa teológicamente, desde este fundamento filosófico, los problemas de la naturaleza y la gracia. Hacia este horizonte apuntamos ahora. Antes de adentrarnos en el tratamiento del problema, conviene recordar que para Zubiri (1997, p. 87) "el hombre no solamente se encuentra en el cristianismo con un acceso a Dios, sino con que Dios mismo es el acceso a Dios".

\subsection{La deificación del hombre:}

Cuando Zubiri se refiere al cristianismo piensa que no se le debe considerar, primariamente, como una religión de salvación que se arraiga en la indigencia de la vida. El cristianismo, según nuestro autor, es una religión de "deiformación" que apunta a la plenitud de la existencia humana:

"El Cristianismo es formalmente, en expresión paulina, una mórphosis (cf. $R m$ 2, 20), una conformación divina del hombre entero; en mi interpreta- 
ción una deiformidad. El Cristianismo es salvación sólo porque es deiformación. Es uno de los puntos en que me parece insuficiente la teología actual. El Cristianismo se dirige primariamente al ser entero del hombre y no a su caída en pecado y menos aún a las fallas de su vida. El Cristianismo no es una argamasa que remienda las fisuras de la vida. El Cristianismo, a mi modo de ver, dirá al hombre actual que su vida es lo que es precisamente porque el ser del hombre es deiforme; $y$ lo es no en sus fracasos sino primaria y principalmente en sus propios logros" (Zubiri, 1997, pp. 18-19).

Zubiri ve en la misma naturaleza del hombre una relación estrecha con Dios. El hombre mismo es deiforme. Esto es algo que no es un atributo o propiedad del ser humano, sino que es lo formalmente constitutivo de él. Al respecto $\mathrm{Zu}$ biri (1997) afirma que deiformidad:

\begin{abstract}
"es, a mi modo de ver, lo primario y radical del Cristianismo: el hombre es deiforme. La deiformidad no es un atributo o propiedad del hombre, sino que, en mí pensar, es lo formalmente constitutivo del ser humano. El hombre es la proyección ad extra de la vida misma de Dios. Ser hombre es una manera finita de ser Dios: es ser Dios humanamente. Lo que Ilamamos "naturaleza humana" no es sino este momento de finitud" (p. 616).
\end{abstract}

Zubiri entiende que todo ser personal, por el hecho de ser persona, se encuentra referido a la persona de quien recibió su propia naturaleza. Por esta razón, "la persona está esencial, constitutiva y formalmente referida a Dios y a los demás hombres" (Zubiri, 2008, p. 160). La dona- ción de Dios, el ágape, es la que nos conduce hacia Dios y hacia los demás seres humanos.

La perspectiva zubiriana en lo referente a la naturaleza del hombre es esencialmente optimista. El acento no está puesto en la lejanía entre la creatura y el Creador, ni tampoco en la dimensión del pecado, sino en que el hombre es proyección finita de la vida divina. Es la incorporación de Dios a la vida humana y, por otro lado, la incorporación del hombre a la vida divina.

En un curso inédito dado por Zubiri en $1968^{14}$, el filósofo vasco plantea que lo más propio de la fe cristiana es la confianza en que Dios nos justifica gratuitamente. Zubiri insiste, en su exégesis de Mateo. 22, que el gran milagro del evangelio es el perdón de Jesús a los pecadores. Los pecadores -prostitutas y publicanos- se reconocen acogidos y perdonados gratuitamente por Dios. La gratuidad de Dios es anterior a nuestras acciones.

\subsection{Cristo y el hombre:}

¿Cómo se produce esta incorporación de la humanidad a la vida divina?: a través de Cristo. Cristo es el camino que enseña cómo el hombre se puede hacer Dios y cómo Dios ya se ha hecho hombre:

$$
\begin{aligned}
& \text { "es la incorporación personal de Dios } \\
& \text { al hombre en la realidad de Cristo. En } \\
& \text { su virtud, toda deiformidad se halla } \\
& \text { fundada en Cristo, toda vida personal } \\
& \text { es una opción respecto de Cristo, y la } \\
& \text { historia entera es un proceso hacia } \\
& \text { Cristo y desde Cristo: es el Cristianis- } \\
& \text { mo. El Cristianismo no es sino la índo- }
\end{aligned}
$$

\footnotetext{
${ }^{14}$ Cita de Corominas (2008, p. 263), del curso inédito de Zubiri, "El hombre como problema de Dios".
} 
le "crística" de la deiformidad. El Cristianismo es la vida humana como experiencia teologal de deiformidad. Es la experiencia que enseña cómo el hombre se puede hacer Dios viendo cómo Dios se ha hecho hombre" (Zubiri, 1997, pp. 616-617).

Repetitivamente hemos dicho que el hombre es una esencia abierta. Está abierto sustantivamente a todo $y$, en primer lugar, a sí mismo. Pero el hombre no sólo está abierto a las cosas y a su misma realidad; está abierto a la realidad en tanto que realidad está abierto a la realidad de Dios. En esta apertura, por una entrega de fe, el hombre cree descubrir a Dios, un Dios personal y vivo. Esta es una experiencia que se manifiesta en todo hombre, en cada situación histórica y en toda religión.

Aunque Dios está manifiesto a todo hombre, puede manifestarse libremente como quiera, incluso a través de su propia encarnación.

Zubiri piensa que Cristo es el fundamento de la historia y que él es a su vez histórico. La historia contiene a Cristo y, además, tiene un carácter específico y formalmente crístico. La historia entera es el cuerpo de Cristo distendido a lo largo del tiempo y en todas las situaciones en que la humanidad se va constituyendo, según señala nuestro autor. Así, Dios es fuente del hombre en su propio ser y en el decurso de la historia. La historia es la forma en que Cristo se incorpora a la humanidad en forma histórica.

El ser humano es una esencia abierta que tiene como primera función constituirse a sí mismo, a su propio ser sustantivo. Cristo tiene un papel fundamental en la vida del hombre. A través de él el hombre constituye y configura su propio ser sustantivo. Esta constitución del hombre, apelando al poder de lo real y al Dios que lo funda, tiene tres dimensiones: ${ }^{15}$ la realidad como aquello último en que el hombre se apoya; la realidad como posibilitante (es el elenco de posibilidades para tener su ser sustantivo). Finalmente, la realidad como impelente: aquello que lo empuja a vivir. Estas tres dimensiones se unen en el acceso del hombre a Dios a través de Cristo.

¿Cómo se dan estas tres dimensiones en Cristo? Primeramente, como realidad última. Jesús habla en la última cena de "conocer" (Juan 17:3). Le pide al Padre que los discípulos lo conozcan (" $Y$ en esto consiste la vida eterna, que te conozcan a ti...y a quien has enviado, a Jesucristo"). Para Zubiri este "conocer" no es el conocer griego, sino el hebreo. No es el conocer teórico, sino el conocer íntimamente algo. Este es el sentido que, según Zubiri, usa Cristo. De esta manera Cristo se nos presenta como el camino único para ese conocer que es la posesión de la realidad misma de Dios.

En segundo lugar, Cristo se nos presenta como la realidad posibilitante. Él mismo dice "Yo soy la vid y vosotros los sarmientos...separados de mí no podéis hacer nada." (Juan 15:5). Sin Cristo no hay posibilidad de acceso a la vida eterna. Él es el acceso.

Por último, está la dimensión impelente. San Juan repite una y otra vez el mandamiento del amor. Es un impeler y empujar. Este no significa hacerlo de ma-

\footnotetext{
${ }^{15}$ Estas tres dimensiones ya fueron aludidas en la primera parte del trabajo. Zubiri toma estas tres dimensiones y las elabora a partir de la figura de Cristo.
} 
nera ciega o terca. Es con respeto a la libertad; no hay un forzar. Este impeler es el amor. Es un impeler amorosamente hacia el amor. De esta manera se superaría el pelagianismo:

"Precisamente el haber confundido ambas dimensiones del problema, $y$ el haber creído que lo que el mandato supone es una decisión automáticamente suficiente por parte del hombre, de atacarlo o rechazarlo, es lo que siglos después constituyó el gran y profundo error de Pelagio: creer que la iniciativa, por lo menos en última instancia (como decía el semipelagianismo), o la condición suprema y primaria de todo acceso del hombre a Dios a través de Cristo es una decisión natural del hombre. Esto es absolutamente falso. No se encontrará nunca en la historia, ni puede encontrarse, un hombre reducido a su condición natural. Todo hombre está, sépalo o no lo sepa, quiéralo o no lo quiera, movido por el amor interno que constituye la realidad metafísica de Dios" (Zubiri, 1997, p. 80).

San Juan repite una y otra vez que Dios es amor (áyá $\pi \eta)$. Es por eso que el mandato o, mejor dicho, el impulso que Dios da a la vida es el mandato o impulso del amor. Este amor no es un mero sentimiento, sino donación real y efectiva. Este donarse a los otros implica un donarse hacia sí mismo, pues el hombre es una realidad que tiene que configurar su ser sustantivo. El hombre tiene que hacerse a sí mismo con cierto esfuerzo: " $Y$ precisamente este esfuerzo va inscrito en esa instancia suprema que es justamente el amor con que Dios impele al hombre a través de Cristo" (Zubiri, 1997, p. 81). El hombre está impelido a darse a los demás de manera radical. El mismo San Pablo lo dice de manera gráfica: "Aunque repartiera todos mis bienes, y entregara mi cuerpo a las llamas, si no tengo caridad, nada me aprovecha." (1 Corintios 13:3).

El sentido último de la vida lo da Cristo. Este sentido es esencial a la vida humana: la donación que se muestra en su totalidad absoluta al ver a Cristo en la cruz. Cristo da en sí pleno sentido a la vida del hombre:

" $Y$ es que en el fondo todos somos viadores. Somos todos viadores, en camino a una configuración permanente de nuestro propio ser sustantivo. $Y$, por esto, la intervención de Cristo en cada vida no es sino la incorporación cada vez mejor a él en virtud del esfuerzo interno, montado precisamente sobre un sentido de vida que sólo él nos $\mathrm{da}^{16}$. Vivir justamente como él vivió para darse a los demás y para darse a la historia. Cristo no es que no haga incompatible la vida, es que exige positivamente la potenciación misma de la vida" (Zubiri, 1997, p. 83).

\subsection{Trinidad}

Anteriormente hemos visto como Dios es fontaneidad de la creación y del ser humano. Dios mismo se da en las esencias cerradas $y$, especialmente, en las esencias abiertas. Por otro lado, tenemos claro que el cristianismo es "deiformación" del hombre que se dirige a la plenitud de la existencia. Cristo mismo señala el camino de deificación; camino que significa donación amorosa absoluta.

\footnotetext{
${ }^{16}$ El editor del libro señala que en este punto Zubi-

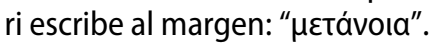


El punto por tratar ahora es la afirmación de que el hombre es una proyección ad extra de la vida misma de Dios. ¿Cómo es esto posible?

Según Zubiri, la creación querida por Dios es la plasmación ad extra de su propia vida trinitaria ${ }^{17}$. Nuestro autor se opone a la dualidad natural/sobrenatural: "lo que llamamos naturaleza es tan sólo la finitud esencial con que la vida trinitaria se realiza ad extra" (Zubiri, 1997, p. 173). Hay tres conceptos que definen la creación por parte de Dios. Estos son: procesionalidad, éxtasis e infinitud. La primera de ellas, procesionalidad, significa que el acto creador posee carácter vital, es una verdadera procesión (aunque no trinitaria):

"la creación es una especie de movilización de la esencia divina para la procesión de criaturas ad extra del Padre por el Hijo en el Espíritu Santo... Así como en las procesiones trinitarias se constituye la esencia infinita de Dios, así también en la procesión creadora se constituye la esencia finita de las cosas" (Zubiri, 1997, pp. 176-177).

La creación es pura donación libre de Dios. Una donación cuya única razón es conferir realidad.

Sobre lo extático, Zubiri señala que Dios es inmensamente fecundo. Por esta razón él no está abierto solamente a su propia realidad, sino que está abierto a otra realidad. En cuanto a infinito, de la fecundidad infinita de Dios resulta la creación. Dios no se separa de la creación. No la deja a su devenir. Ella es lugar en que se

${ }^{17}$ Cfr. Zubiri (1997, p. 172). realizan intervenciones divinas: "este mundo abierto que se va conformando es pura y simplemente el devenir teologal de las iniciativas divinas" (Zubiri, 1997, p. 196).

Al referirse a las esencias abiertas Zubiri construye una verdadera antropología teológica. Las esencias abiertas son la plasmación formal ad extra de la propia vida trinitaria de Dios (teniendo en cuenta que la naturaleza de ellas es finita). ${ }^{18}$

Tomando Génesis 1:26, Zubiri dice que el hombre es lo más parecido al Creador. El ser humano es imagen y semejanza divina. La realidad humana es la plasmación ad extra relativamente absoluta de la vida trinitaria de Dios:

“Ciertamente, el autor de Gn 1, 26 ha pensado al menos en una cosa para él más importante: que aquello en que se parece el hombre creado por Dios a los 'Elohim, y especialmente al 'Elohim creador, no está en su figura y en su forma; está en otra cosa más honda. Es lo que dice a continuación el texto: que domine y sea dueño del universo entero (cf. Gn 1, 28). Aquí se acerca más a la realidad de Dios que a lo creado. El hombre, en una o en otra forma, participa de este dominio, que Dios le otorga, del universo material entero $y$, en este sentido, es una imagen todavía más honda de Dios" (Zubiri, 1997, p. 208).

El hombre es imagen y semejanza de Dios. Imagen no significa identificación, pues, como hemos visto, el hombre es la vida ad extra de la vida trinitaria. El ser humano es Dios finito.

${ }^{18}$ Cfr. (Zubiri, 1997, p. 204). 
Según Zubiri, no se trata de buscar en el hombre la imagen de la Trinidad (cosa que sería legítima), sino justamente al revés: la idea es partir de la Trinidad como fundamento del hombre. Es el fundamento que hace posible las estructuras del ser humano. El hombre es una proyección ad extra de la divinidad. En palabras de Zubiri (1997): "La persona humana es la forma finita de ser como Dios, es decir, teniendo inteligencia y voluntad, y además vivir como él vive: trinitariamente" (p. 214). Realidad, ser e intimidad funcionan trinitariamente, y su raíz unitaria es la libertad. Por su libertad, el hombre participa de la soberanía e independencia divina (aunque de manera finita). Por esta misma libertad el hombre se va haciendo a sí mismo: se realiza divinamente. Zubiri (1997) dirá: "la creación del hombre como esencia abierta es la voluntad de deiformación de su vida en libertad" (p. 216).

\subsection{Gracia}

Luego de analizar al hombre como esencia abierta que revela la vida ad extra de la trinidad, Zubiri se preguntará en qué consiste el decurso real y efectivo de la vida del ser humano.

En primer lugar, según nuestro autor, la esencia abierta tiene un decurso biográfico 19: "La voluntad de deiformación es, por parte de Dios, ante todo y sobre todo una voluntad de deiformación biográfica" (Zubiri, 1997, p. 216).

En el decurso biográfico Dios aparece subyaciendo fontanalmente a toda realidad creada y, especialmente, al hombre. ¿Cómo se manifiesta esta fontanali-

\footnotetext{
${ }^{19}$ Biográfico significa cómo el hombre se va haciendo sustantivamente a sí mismo en la realidad.
}

dad en la vida del hombre? Zubiri (2017) dirá que a través de la gracia: "esta presencia fontanal de la realidad divina dentro del hombre se expresa en un concepto sumamente preciso, que es Xápıs, gratia". (pp. 216-217).

Gracia no significa el carácter trinitario del hombre. Este (el carácter trinitario) es fundamento de que haya gracia, pero no es gracia en sí mismo. El hombre tiene el carácter trinitario, pero además tiene la gracia. Esto se da porque el hombre no sólo convive "en" un Dios trinitario y trinitariamente, sino que convive además "con" Dios:

"Y, por eso, la mayoría de las cosas
que el hombre siente en su vida, que
tranquilamente en su propia percep-
ción piensa que son cosas que emer-
gen naturalmente de uno, son en su
inmensa mayoría obra de la gracia. Y,
desde luego, todas, sin excepción, son
formalmente el trasunto de la propia
divinidad trinitaria de Dios" (Zubiri,
1997, p. 217).

Esta gracia no es gracia impuesta, sino en libertad. Esta libertad trae aparejada la posibilidad de rechazar la gracia; del pecado: "Un pecado no es una falta moral, sino que consiste precisamente en una aversión de Dios, más o menos temática, más o menos agresiva, etc." (Zubiri, 1997, p. 217).

¿Cómo se da la gracia a través de Cristo? La resurrección tiene la misión de propagar el cristianismo sobre la tierra (Zubiri, 1997, pp. 334-335). La resurrección es un acto numéricamente uno de plasmación del Cristianismo en cada una de las personas a las que llega. San Pablo lo describe cuando habla del bautismo (cf. 
Romanos 6:3-11). Con la muerte de Cristo nosotros hemos muerto al pecado y hemos pasado a una vida diferente, superior. Es la plasmación de ese tránsito de la tierra a la diestra del Padre en el ser de cada uno de los hombres. La resurrección de Cristo es una plasmación del ser del hombre. ¿Qué produce esta plasmación?: "Justamente el que el ser, que de una manera radical era aversivo a Dios por estar bajo el poder del mundo, se convierte ahora en un ser que de manera radical es, o puede por lo menos ser, conversivo hacia Dios" (Zubiri, 1997, p. 334). La resurrección plasma el ser del hombre como hombre nuevo, revestido de Cristo, destinado -en la resurrección - a tener un cuerpo pneumático. Es la paliggenesia, regeneratio. Esta regeneración no es, para Zubiri, la plasmación ad extra de la vida trinitaria. Es algo distinto:

\begin{abstract}
"Es dar a esta plasmación trinitaria ad extra la capacidad de estar ella misma dentro del poder de Dios. La

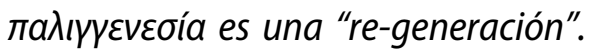
Es decir, al ser del hombre lo sacan de la condición de estar sometido al poder del pecado y queda sometido al orbe del poder de Dios... Entonces 10 que pone en el regenerado es precisamente el poder de Dios en él. Y el poder de Dios en él es lo que (desde este punto de vista) merece llamarse Xápıç, gracia" (Zubiri, 1997, pp. 335336).
\end{abstract}

Para Zubiri la gracia no es una especie de "ducha" que viene desde fuera, sino la inserción intrínseca dentro de la plasmación en que trinitariamente consiste la realidad del hombre mientras está en el mundo. La escolástica, de manera muy aristotélica, pensó en la gracia como la cualidad de una substancia, un habitus. Nuestro autor no comparte esa idea:

"No hay por qué pensar que la gracia es la cualidad de una substancia. Es algo mucho más rico: es el poder de Dios en la vida efectiva y real del hombre, el poder con que el hombre va haciendo su propio ser sustantivo. El poder de Dios en nosotros nos hace ser deiformes. Este poder de Dios no es un auxilio que viene de fuera, sino que la resurrección de Cristo ha plasmado en el seno del espiritu del hom-

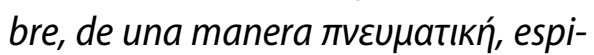
ritual, la presencia de esa Trinidad en cuya plasmación consiste la realidad formal del hombre, como fuente de ese poder de Dios en cada uno de nosotros" (Zubiri, 1997, p. 336).

La gracia es el poder de Dios en la vida real del ser humano. A través de ella el hombre va haciendo su propio ser sustantivo, que no es sino hacerse deiforme.

En vista de lo anterior, la vida de la gracia no es una experiencia psicológica. No es, tampoco, un mero hábito. Es experiencia moral vivida a la luz de la fe. El hombre tiene la experiencia de la gracia a lo largo de toda su vida.

Crucifixión y resurrección no son dos actos separados, según Zubiri. Es un solo acto que es un acontecimiento real que tiene por fin "colocarnos bajo el poder de Dios por una regeneración interna en la gracia y por la incorporación" (Zubiri, 1997, p. 337). Muerte y resurrección de Cristo regeneran al hombre por la gracia. En este punto nuestro autor se pregunta si estos actos ocurrieron sólo una vez y para siempre. La respuesta es negativa: "Pues bien, hay que contestar que estos actos no ocu- 
rrieron una sola vez; se van repitiendo a lo largo de la historia de la humanidad" (Zubiri, 1997, p. 338). Evidentemente estos actos, como acciones históricas, dejaron de pasar, pero, en tanto que fundantes del Cristianismo, estas acciones no son transitorias, sino permanentes. Zubiri entiende que ellas se han ido repitiendo en la historia a través de los sacramentos.

Los sacramentos reproducen la acción de Cristo en su muerte y resurrección. El cristiano recibe estos actos de Cristo mismo, de manera que, a lo largo de su vida, va muriendo cada vez más al pecado y revistiéndose de Cristo:

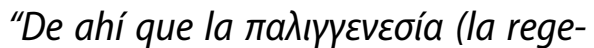
neración) en que consiste la participación en la muerte y resurrección de Cristo no sea algo que tiene un carácter meramente extrínseco, sino que consiste precisamente en que en nosotros, de una manera progresiva, va estando presente el poder de Dios como consecuencia de una presencia intrínseca de la divinidad misma" (Zubiri, 1997, p. 343).

Ciertamente estas acciones producen gracia, pero no son como una "tableta de aspirina" (Zubiri piensa que por cuatro siglos se ha malentendido Trento, en el sentido de considerar que la gracia actúa por sí misma, como una especie de tableta de aspirina). Es necesaria la recepción del sacramento, de la gracia. No es sólo no oponerse al sacramento, sino que tener un cambio del corazón, una

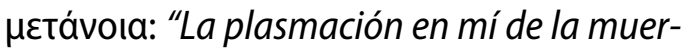
te y resurrección de Cristo es una transformación personal e intrínseca de mi ser. Requiere, por tanto, una colaboración interna e intrínseca de mí mismo" (Zubiri, 1997, pp. 346-347).
El Cristianismo, el ser cristiano, se va plasmando en cada persona a través de las acciones de Cristo. Acciones que suceden de manera permanente a través de la historia; que se repiten permanentemente en los sacramentos. Así, cada cristiano ha recibido la acción de Cristo, que no es sino la gracia de morir cada vez más al pecado y revestirse de Cristo.

\section{Conclusiones}

La pregunta guía de esta investigación ha sido "¿Cómo/dónde se encuentra Dios con el hombre?". Teniendo esta pregunta en mente es que hemos dialogado con Zubiri a través de algunos de sus textos, de manera que nos puedan ayudar a dar una respuesta a nuestro preguntar.

¿Cómo y dónde se encuentra Dios con el hombre y el hombre con Dios? En la realidad. Esta es la respuesta radical de nuestro autor. La realidad es el momento fundante de todo pensar (como el momento más originario desde donde el ser humano puede preguntar y situarse) $y$, por sobre todo, es el lugar radical donde el hombre se hace hombre.

La realidad, no la conciencia intencional o el sentido ${ }^{20}$, es el lugar radical desde donde el ser humano se hace y es. El hombre está instalado en la realidad. Ella tiene poder, en el sentido que ella posee al ser humano de una manera irresistible. Este poder de la realidad es fundante del hombre. Este poder lanza al hombre hacia la realidad, hacia el mundo, si se puede decir. El hombre está impelido a ir haciéndose sustantivamente en su propia vida, en la sociedad, en la historia. ${ }^{20} \mathrm{Al}$ contrario de lo pensado por Husserl y Heideg-
ger. 
El ser humano está ligado a este poder de lo real. Esta ligazón es religación al poder de lo real que se impone al hombre. Al final esta religación es al fundamento de toda la realidad: Dios. Para Zubiri Dios es la realidad última. Realidad que impele al hombre. Dios es la posibilidad fundante y constituyente de la vida humana. Dios hace una auto donación de sí mismo, pues él es pura donación.

Zubiri, al igual que Heidegger, critica la ontoteología, pues piensa que por siglos se ha hecho a Dios un objeto óntico; es decir, se ha sido pensado como un ente más: el mayor de todos, el más perfecto e infinito, pero un ente al fin y al cabo. Contra esto Zubiri plantea a Dios como experiencia del fundamento último de todo, de la gracia gratuita.

El cristianismo es, antes que religión de salvación, una religión de deiformación. El cristianismo no es una "argamasa" que repara las fisuras de la vida del hombre, sino que apunta a la totalidad de la vida humana, al ser del hombre.

Para Zubiri el hombre, como esencia abierta, recibe la total donación personal de Dios. Esta donación divina hacia el hombre es parte ontológica del ser humano. No es un agregado al ser humano.

En todo el pensamiento zubiriano hay un optimismo radical en torno a la naturaleza humana. El hombre es la expresión ad extra de la vida trinitaria. Es, por lo tanto, Dios de manera finita. Hay, por tanto, una unión radical entre el en Creador y la creatura.

Este pensamiento es esencialmente católico, pues niega implícitamente la separación radical entre Dios y hombre. El ser humano "muestra a Dios", está íntimamente ligado a él. La vida ad extra de la Trinidad se puede "palpar" en la vida del ser humano. Todo hombre, a lo largo de la historia y en cualquier religión, siente, de una forma u otra, está fundamental unión (religación) con el Creador. Es por eso por lo que el hombre siempre ha hecho y hará el camino hacia Dios. Está, como Zubiri dice, impelido libremente por el amor de Dios a buscar su fundamento último. Este fundamento no es otra cosa que Dios.

El hombre no convive solamente "en" Dios, sino que, además, "con" Dios. Esto significa que la gracia llega a ser, de alguna manera, parte de la vida natural del hombre. Es así que el ser humano percibe en su vida la gracia, pero no se da cuenta, en cada momento de su existencia, de ella.

Dios se hace carne en Cristo para que la carne, el hombre, se haga Dios. En Cristo reconocemos el camino para alcanzar a Dios. Cristo mismo nos muestra la vía, a través del mandamiento del amor, para llegar al Creador.

La muerte y resurrección de Cristo implican una regeneración del hombre. Este hombre que era "aversivo" a Dios por estar bajo el poder del mundo, se convierte en un ser conversivo a Dios mismo. Por la regeneración el hombre deja de estar sometido al poder de pecado y queda sometido al poder de Dios. Este quedar sometido al poder de Dios es lo que se llama gracia.

El mismo acto de Cristo de morir y resucitar (considerado como uno sólo por Zubiri), se repite una y otra vez a través de la historia en cada hombre que recibe los sacramentos. Ellos donan la gracia de la 
muerte y resurrección de Cristo, haciendo que el hombre muera al pecado y se revista con la vida de Dios. Los sacramentos actúan ex opere operato, pero no son, en palabras de Zubiri, como una "tableta de aspirina", pues ellos no se administran a un leño, sino que a una persona. Por eso es importante la actitud de la persona que los recibe: se necesita una condición positiva, que es la fe y conversión de corazón.
Frente a la pregunta de cómo y dónde se encuentra el hombre con Dios, la respuesta es en la realidad. Al decir "realidad" ya estamos hablando, en último término, del encuentro del hombre con Dios.

\section{Referencias Bibliográficas}

Conill, J. (2006). De la religión de la vida a la religión personal en Ortega y Zubiri. The Xavier Zubiri Review, 8, 93-101. Recuperado de http://bit.ly/2kL9B2l

Conill, J. (2009). La voz de la conciencia. La conexión noológica de moralidad y religiosidad en Zubiri. Isegoría, (40), 115-134. doi: 10.3989/isegoria.2009.i40.648

Corominas, J. (2008) Xavier Zubiri y la religión. Puebla: Universidad Iberoamericana Puebla.

Ellacuría, I. (1999). Escritos filosóficos (Vol. 2). San Salvador: UCA Editores.

Gracia, D. (2013). ¿Pero qué es la religación? En J. San Martín y J. J. Sánchez (Ed.), Pensando la religión. Homenaje a Manuel Fraijó (pp.173-195). Madrid: Trotta.

Gracia, D. (2010). Religación y Religión en Zubiri. En M. Fraijó (Ed.), Filosofía de la religión: estudios y textos (pp. 491-512). Madrid: Trotta.

Gracia, D. (2006). Zubiri y la filosofía de la religión (1934-1944). The Xavier Zubiri Review, 8, 59-92. Recuperado de http://bit.ly/2m2ukyG

López Aranguren, J. (1981). Ética. Madrid: Alianza Editorial.

Pintor Ramos, A. (1996), Génesis y formación de la filosofía de Zubiri, Salamanca: Universidad Pontificia de Salamanca.

Pintor Ramos, A. (1993). Realidad y sentido. Desde una inspiración zubiriana. Salamanca: Universidad Pontificia de Salamanca.

Rivera, J. (2001). Heidegger y Zubiri. Santiago de Chile: Editorial Universitaria, Universidad Católica de Chile.

Zubiri, X. (1995). Estructura dinámica de la realidad. Madrid: Alianza Editorial.

Zubiri, X. (1998). El hombre y Dios. Madrid: Alianza Editorial.

Zubiri, X. (1974). Naturaleza, historia, Dios. Madrid: Alianza Editorial. 
Zubiri, X. (1997). El problema teologal del hombre: cristianismo. Madrid: Alianza Editorial.

Zubiri, X. (2008). El ser sobrenatural: Dios y la deificación en la teología paulina. En G. Díaz Muñoz, Teología del Misterio en Zubiri. Barcelona: Herder, Barcelona.

Zubiri, X. (1985). Sobre la esencia. Madrid: Alianza Editorial.

Zubiri, X. (2017). Sobre la religión. Madrid: Alianza Editorial.

Para citar este artículo bajo Norma APA 6a ed.

Sepúlveda del Río, I. (2019). Religación y Gracia en el pensamiento de Xavier Zubiri. Cuadernos de Teología Universidad Católica del Norte (En línea), 11, e3541, https://doi.org/10.22199/issn.0719-8175-2019-0003

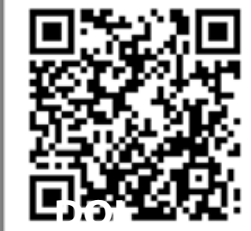

DOI

Copyright del articulo: @2019 Ignacio Sepúlveda

Este es un artículo de acceso abierto, bajo licencia Creative Commons BY 4.0 